\author{
Robert Michael Regoli \\ Washington State University
}

\begin{abstract}
Social scientists have an intuitive notion of what "power" infers, but have been unable to define it rigorously enough for use in a systematic study of this social phenomenon. Adopting a social systems perspective, the paper focuses on the historical development, empirical utility, and the integration of the theoretical dimension of the concept. In addition, the process by which subsystems form larger operating units is explored with attention being given to the development of power relationships among them.
\end{abstract}

\title{
Introduction
}

Most social scientists have an intuitive notion of what 'power' means. Yet, social scientists have been unable to formulate a statement of the concept that is rigorous enough to be used in a systematic study of this important social phenomenon. The more social scientists attempt to define power, the more complex it is found to be.

To say that certain individuals have more or less "power" than others is one of the palpable facts of human existence. Parent-child, chiefpatrolman, professor-graduate student, professional-amateur are all relationships which imply the notion of power (Peabody, 1964). The concept of power is as ancient as any that social theory can boast. To document this assertion, one could cite a series of social philosophers from Socrates, Plato, and Aristotle through Machiavelli and Hobbes to Pareto, Mosca, Weber and Durkheim to demonstrate that a large number of seminal theorists have devoted a great amount of their thought to the concept of power and the implications associated with it (Dah1, 1957).

Because so many social scientists, at varying times in history have felt the need to attach the label 'power' to some Thing they bel ieved they had observed, one is tempted to think that the Thing must exist. Beyond existing, the Thing must be of a form capable of being studied in an empirical manner. Many social scientists have thought of power as existing even in a "potential" state. The notion of "potentiality" has persuaded social scientists to use indirect measures of power and of ten it has prompted them to ask rhetorical questions about the relationship between desirable social facts (e.g., class stratification) and power.

Another group of theorists have conceived of power as being 'actual'. Simply, $(\underline{X})$ has power over $(Y)$ to the extent that he $(X)$ can yet $(Y)$ to do something that $(\underline{Y})$ would not otherwise do. This definition al lows its 
users to empirically look at power relations, whereas those theorists who describe power in terms of 'potentiality' find it much more difficult to rely on empirical verification (Daht, 1957). More attention will be given to the limitations of both of these approaches further on.

\section{Definitions of Power}

Al though social scientists define power in a multitude of ways, most of them understand what others mean when they use the concept of 'power'. One common factor in all definitions of power is the agreement that the concept infers a certain amount of displacement of energy. A sample of the spectrum of definitions of power that one is likely to discover in reviewing the literature follows:

Blau: Power is all kinds of influence between persons or groups, including those exercised in exchange transactions, where one induces others to accede to his wishes by rewarding them for doing so. (B1au, 1964)

Brown: Power is the influence exerted by a man or a group, through whatever means, over the conduct of others in intended ways. (Hoult, 1969)

Goldhammer and Shils: A person has power to the extent that he influences the behavior of others in accordance with his own intentions. (Goldhammer and Shils, 1939)

Weber: Power is the probability that one actor with in a social relationship will be in a position to carry out his own will, despite resistances, regardless of the basis on which this probability rests. (Weber, 1947)

Bierstedt: Power is latent force. (Bierstedt, T950)

Hobbes: Power is a man's ability to obtain some future apparent goods, (Parsons, 1937)

Lasswell and Kaplan: Power is participation in the making of decisions. (Lasswell and Kaplin, 1950)

Parsons: Power is an actors ability to induce or infTuence another actor to carry out his directives or any other norms that he supports. (Litterer, 1968)

Banfield: Power is the ability to establish control over another. (Banfield, 1961) 


\author{
Dahl: (A) has power over (B) to the extent that \\ (A) can get (B) to do something that (B) would \\ not otherwise do. (Dah1, 1957)
}

These orientations towards the concept of power can be categorized into two specific schools of thought towards the concept. The first of these schools can be labeled the individualistic school. This school of thought is represented in Weber's definition of the concept, as well as in, the definitions of Goldhammer and Shils, Hobbes, Banfield, and Parsons. Focusing upon Weber's definition of the concept, it is recognized that his orientation to 'power' perceives power as focusing on the probability that single actor achieves his desired goals. Weber's definition, and those who accept his notion of the concept, is sociologically limiting in that it does not consider other actors, nor does it consider the social structure of the system with in which the action takes place. (It should be pointed out that an 'actor' is not restricted to an individual, but rather, an 'actor' can be an individual, group, complex organization, etc.) (Áiken and Mott, 1968.)

A second school of thought is represented by theorists who have gathered around Robert Dahl. Dahl, and his followers, have developed a dyadic orientation towards the concept. From Dahl's orientation, power is conceived of as a relationship between two actors, where one actor is able to bring about a change in the second actor. For Dahl, this change is represented as an alteration in activity, belief, or something else (Dah1, 1957). Essentially, this school of thought sees power as a relational variable. Quite obviously, a major limitation of this school is that it does not make any reference to goals or to the broader social structure. This school of thought is solely concerned with the situation where $(X)$ has power over $(Y)$ to the extent that he can get $(Y)$ to do something that $(Y)$ would not do otherwise.

A fundamental distinction between the individualistic school and the dyadic school is that those theorists who hold to the latter position perceive power as a forcing or persuading attribute in a person or a relationship, (a relational variable) whereas those theorists who ascribe to an individualistic orientation imply power to exist in the potential or the capacity to act.

For this paper, power is perceived to be more than what is implied by either of these two orientations. We do not disagree with the implication of the individualistic oriented theorists who argue that power can reside in the potential to act; power is more than that. In this paper, 'power' will be considered to be: the potential ability of an actor or actors to select, to change, and to attain the goals of the social system with in which they operate. Contrasting this approach to those previousty stated, we can see that it differs considerably from either of the schools just discussed. First, power is not an attribute of a single actor. If this were true, then an implication evolving from this would be that the actor who is powerful in one social system is equally powerful in another. We suggest that an individual actor can be considered powerful only in terms of the social structure that he is operating within. Furthermore, it is difficult (if not impossible) for an actor to transfer his power to a second social structure in a manner so that his power in the system he transferred to is as great in the beginning as it was in the system from 
which he transferred. Secondly, power is not seen as a property between two actors. Even though an actor may have a great deal of influence over a second actor in one system, the relationship may change when the two actors are in a second social structure. Furthermore, it is simplistic to perceive of power as existing in a dyadic relationship. (As Dahi and others do.) This paper advocates the position that a 'power relation' can exist between more than two actors, and quite often does.

The orientation put forth in this paper emphasizes as its basic unit actors who are operating in one or more status positions within a specific social system. This orientation focuses on the abilities of various actors to restrict the inputs into the system, to convert the imputs into specific demands, to redirect the flows of decisions within the system, and to regulate the output of the system. (This approach concerns itself with "dual power positions.") Further, this orientation considers the potential ability of actors to bring about changes in a particular social system, hence, we speak: of power structures.

\section{Properties (Dimensions) of Power}

For the purposes of clarification, the concept of 'actor(s)' is not confined to individuals, but rather, 'actor(s)' may be individuals, groups, neighborhoods, communities, nation-states, or any other composite of human aggregates. In a group there is no individual action operating independently of the group. Within a group there is joint action or individuals' actions representing the entire group.

From a review of the literature, seven properties of power have been developed. Each property is discussed below so that a more complete understanding of the concept of power will emerge.

(1) Power refers to a relation among two or more things. Power does not necessarily have to exist between two or more animate objects. A person, group, or community can have power over a certain inanimate object and consequently have power over another actor(s), but the power relation is independent upon the inanimate object. To illustrate; suppose a contractor desires to construct a building which is dependent upon the allocation of city funds. Although the city council has no power directly over the individual, they do have direct control of the funds; thereby giving them indirect control over the contractor. As a result, the power of the allocation of the funds becomes the 1 inkage in the power relationship. Power cannot exist between a single actor and himself, but rather, it involves a relationship between two or more objects so that a power relation can develop in the form of an aggregate. Essentially, power relationships are more than dyadic as was implied by Dahl's constituent.

A power relation can exist whether or not there is a clash of interests between the actors. What is necessary is that one of the actors cause the other actor(s) to alter his/their behavior. In one instance, a power relationship exists when one actor wants a specific task performed in one way and a second actor wants the task performed in another way (clash of interests). Yet, a power relation can also exist when there is not a clash 
of interests between the actors. For example, a boss has power over his secretary al though there is no clash of interests between the two actors (Weber refers to this as authority; which is noncoercive power). The secretary carries out his/her duties because his/her superior represents a symbol of power (potential power).

By inferring power to be a relation among two or more objects, it should be understood that at least two of the objects realize that a relationship exists between them. Suppose a person stands on a street corner and says to himself, "I demand that all automobile drivers on this street drive on the right-hand side of the road"; suppose further that all the automobile drivers actually did as the individual commanded them to do; still, many people in our society would consider the person to be mentally ill (deficient) if the person continued to insist that he had enough power over automobile drivers to compel them to drive on the right-hand side of the road. Suppose, however, that a law enforcement officer is standing in the middle of an intersection at which the traffic moves towards him; he orders all of the automobile drivers to turn right or left; they move as he orders them to do. Acting in his particular role, the law enforcement officer has the power to compel the drivers to follow his directives, whereas few people would argue that the person on the street corner had this power (Dahi, 1957).

(2) "Power Potentiality." Alterations in an actor's behavior does not have to be the result of an overt action by the powerful actor, but rather any alterations may be a consequence of 'potential power'. Take the following example: suppose further that he continues to do so until he sees a law enforcement officer, in his patrol car, parked on the side of the road ahead of him. Because the person has observed the law enforcement officer, a symbol of power, there is a high probability that the automobile driver will slow down to the appropriate speed limit. The explanation why the automobile driver will slow down is in relation to the fact that be does not want to receive a citation (negative sanction) from the law enforcement officer; the automobile drive anticipates the police officer's reaction to inis behavior (speeding) if he is caught and alters it.

(3) Time Lag. There mast be a lag in time from the actions of the powerful actor to the responses of the subordinate actor(s). If there is no time $\mathrm{lag}$ between the actor who it is thought exerts power to the response of the other actor(s), how would a researcher determine the powerful actor? For illustrative purposes, refer to the following quotation:

This condition, obvious as it is, is critically important in the actual study of power relations. Who runs the XYZ Corporation? Whenever the president announces a new policy, he immediately secures the compliance of the top officials. But upon further investigation it turns out that every new policy he announces has first been put to him by the head of the sales division, Or again, suppose we had a full record of the times at which each of the top Soviet leaders revealed his positions on various issues; we could then deduce a great deal about who is running the show and who is not. (Dahl, 1957) 
In other words, one actor $(X)$ can hardly be thought to have power over another actor $(\underline{Y})$ unless ( $\left.\underline{X}^{\top} s\right)$ specific power attempts preceed ( $\underline{Y}^{\prime} s$ ) specific responses.

(4) Reciprocal Relationship. A power relationship is often considered to be an asymmetrical interpersonal influence relationship (Clark, 1967). There are essentially two forms of asymmetry that need to be presented. One form of asymmetry in the dyad relationship is primarily based on attraction. One member of the dyad as a result of special qualities attractive to the other member, motivates the person: (1) to want to be with him/her, though not necessarily to follow him/her; (2) to imitate his behavior; and (3) to follow his example or command. (French and Raven refer to this as referent power) (Schermerhorn, 1961). A second form of symmetry in the pair relationship occurs through pressure from above and submission from below. A fundamental distraction between this form of asymmetry and the previously discussed one is that in the case of attraction there is spontaniety, while under pressure there is effort and constraint (Schermerhorn, 1961).

(5) Indirect Influence. Indirect influence is indicative in the situation where one actor influences a second, third, and fourth actor through an intermediary. The distinction between 'power potentiality' and 'indirect influence' then becomes obvious. 'Power potentiality' refers to a recognition of a symbol of power (law enforcement officer, corporation boss, mayor, etc.), whereas, indirect influence refers to the situation where an actor or object (Clark, 1967). (Object is used in this writing to refer to anything that is inanimate.)

(6) Scope of Power. An actor's power does not affect all other actors in precisely the same manner. An actor has more power over certain actors than he does over others (Clark, 1967). For example, the Catholic Church has much more power over members of the church than it does over an atheist!!

(7) Power Legitimacy. Power has a certain degree of legitimacy associated with it, yet it is quite different from what is implied by 'status' or 'prestige' and 'authority'. Status or prestige is a subjective evaluation of an individual or group by 'certain' other people. Power and status (prestige) quite often coincide together in a symbiotic relationship, yet the two concepts are not synonymous. It is quite possible for an individual to have 'status', but little power; like the dethroned king. Also, one may have a lot of power, but little status in the society; like the late mafia leader, Al Capone (Clark, 1967).

Another concept, quite of ten confused with 'power' is 'authority' (Peabody, 1964). Social scientists have attempted to resolve this dichotomy between 'authority' and 'power' by defining the exercise of authority in terms of force with the "general approval" of those concerned. Another way that authority and power have been differentiated is by treating authority and power as different types of relationships among people (Peabody, 1964).

A second distinction between 'authority' and 'power' is that the exercise of authority enables administrators to justify or criticize the actions taken, but the exercise of power per se, bears no such relation. From research conducted, (Regoli, 1971) it is inferred that the pronounce- 
ments of authority are not merely fiats that must be obeyed, but rather, they also function as standards for the individual administrator's own appraisal of their own behavior. When differentiating between authority and power at the community level, it appears as if authority is often implicitly or explicitly denied to people who have power, and it is often invested in people who do not have the ability to bring about force and coercion to bear upon others (Peabody, 1964). Under such circumstances, those in authority positions are considered to be entitled to get others to do certain things, whereas those who are considered to have power alone merely have the ability to force individuals to perform specific tasks. Authority is a subdivision (subunit) of power in that all authority is power, but not all power is necessarily authority.

Realizing various dimensions of the power variable, a question that comes to mind is: What effects does a particular culture have on power relationships? Obviously some; those are referred to in terms of various mechanisms of integration. Much of the literature dealing with the concept of power makes little use of the notion as it applied to entities larger than a group consisting of two people. Furthermore, even when the literature does discuss larger entities, it often fails to discuss the effect of culture on the power relationships within or between entities.

\section{Mechanisms of Integration}

As a social system becomes differentiated, it must integrate its primary subsystems with one another unless it is to disintegrate. There are primarily five mechanisms of integration that will be considered. For purposes of clarity the concept 'integration' means to bring together; "Differentiation means 'becoming different', and for this writing 'social system' refers to a "set of interacting persons or groups, conceived of as distinct from the particular persons who compare it." (Theodorson and Theodorson, 1970.) As defined by Loomis, the social system is composed of the patterned interaction of members. A social system consists of a plurality of individual actors. The individual actors are related to each other in that each seeks goal attainment through the definition of structured and shared symbols of expectations. The reason that individuals participate in social systems is that they feel that through concernted action in cooperation with others they can optimize the attainment of certain goals more easily than if they all worked in opposition to one another. As soon as individuals find themselves in the social system that comes into existence because of this prior choice, they become identified with goals and means which are not those of any one individual, but of the social system. (Bohlen et al., 1965) In a society there are various levels of social systems. Social systems are represented in the interaction of two people, the family, the school, the church, the corporation, the community, and the nation. Characteristic to each of these social systems is that the members interact with one another more than they do with non-members of their social system.

Integration is a functional problem that all societies face when their primary socializing bodies begin to become differentiated. In order for a society to maintain its existence integration must take place. Also, in most societies more than one of these five mechanisms of integration are usualiy operating at the same time. 
General Values: Institutionalized

Before a social system differentiates into sub-systems, there is usually an institutionalized general value system. The general values are reiterated and reinforced by the sub-systems of the social system. This is the point where the importance of societal norms is important. (Clark, 1967)

Normative Reinforcement

A second mode of integration is the inculcation and reinforcement of norms relating to the performance of specific roles in the social system. The principal mechanisms for such integration are the formal and informal organizations of individuals occupying similar statuses. (Clark, 1967)

\section{Bureaucracy}

Bureaucracy, extends from the previous mechanisms for integration, but yet it is a distinctive type in itself. Quite obviously, as long as a bureaucracy has control over two or more subsectors of a social system it has the capability to integrate them with one another. (Clark, 1967)

Juridical System

A fourth mechanism that contributes to this integrative function is the juridical system. The juridical system plays this role by enforcing the general norms and values of the society. The knowiedge that behind a general societal structure of norms and values there lies legal sanction to punish deviants generally suffices to control most people in the society. (Clark, 1967)

\section{Interchange Between Sub-systems}

The interchange referred to here can be anything in the range from symbolic gestures to a specific commodity. The exchange between subsystems leads to the development of role-related norms. These norms that emerge from this interchange between sub-systems can grow into laws and become institutionalized as values of the society (Clark, 1967). It is this mechanism of integration that is considered to be of primary importance for a discussion of the relationship between 'norms' and 'values' in reference to societal power structures.

\section{Interchange-Exchange Among Actors}

Interaction can be considered to be a process of exchange, each of the actors gives to the other actor(s) his time and attention. As actors continue to interact, they communicate their thoughts to one another. As a consequence of this a number of interaction patterns may develop. First of all, if each of the two actors do about half of the communicating and exchange equal amounts of information (or whatever else might be involved) then balanced interaction exists among the actors. However, if one of the 
actors does more communicating, or gives more information than the other actor(s) an imbalance will result. If by chance this situation continues over a long period of time, the actor who is doing all of the giving is likely to get tired of his role. The situation needs to be corrected. This can be done in various ways. The easiest way to rectify the situation is for the actor(s) who has/have been receiving all of the information to begin to return information to the other actor. In doing this, the relationship will move towards a state of equilibrium. By being in equilibrium, the participants are able to react to change in such a way as to minimize the change's impact on the relation between them. (Clark, 1967) A second way to correct the imbalance is for the communication between the actors to be terminated. Here the actors (two, three, or however many) will decide that further interaction is not interesting to any of them, and they may each go their separate ways. A third alternative to correct this imbalance is the creation of a power relation between the actors. For illustrative purposes, let us take the case that involves two actors. It is possible that the silent actor in an impersonal power relationship finds the relationship rewarding, and does not want to terminate it. Further, it is also possible that this actor is not capable of reciprocating with commodities or with information that is considered attractive to the other actor so as to keep him interested in maintaining the relationship. It is at this point that the actor who seeks to continue the relationship must do one of three things. He can try to change the situation within which the interaction takes place. Secondly, he may give the other actor some commodity (i.e., money) that was not initially in the relationship. Third, the actor may offer himself as a commodity in exchange. This is obviously an extension of the second alternative, but the sociological implications raised by this action are many. The most important is that in offering himself as a commodity in exchange the relationship between the two actors taken on a new form. The new form is that an imbalance of power has been established between the actors. (Clark, 1967)

From an exchange theory perspective of power relationship exists when one actor is able to offer something to the other actor(s) that place them in his debt. Whatever intrinsic rewards are defined as valuable by the majority of the actors can create the situation of indebtedness to one actor. For example, the actor who is able to offer efficient means to all of the other actors for the attainment of their goals places all of the other actors in a situation of being indebted to him. This remains the case as long as the attainment of the goals involved are valued by a majority of the actors.

The entire process of exchange and interaction does not terminate here. There are specific norms that dictate the operating procedures of the system. In other words, there are particular 'rules of the game' that further define the power relationship between actors. First of all, the actor (any actor) is obliged to accept a gift that is offered to him. Gouldner argues that it is a 'rule of the game' not to refure a give, especially gifts given with no immediate recippocal action implied. A second norm is that every actor must offer gifts to other actors in the system. A third 'rule of the game' is an extension of the previous two. It is the norm of reciprocity. Reciprocity can be accomplished in more than one way. An actor can reciprocate by giving a gift, one gift is exchanged for another gift. A second way that an actor can reciprocate is that one gift is exchanged for another gift in different sort. Third, certain institutionalized norms such as altruism, can sanction occasional 
exceptions from the norm of reciprocity. Fourth, there may be a large amount of difference in power among the actors in the system so that altruistic norms may be institutionalized as a sort of escape value for pressures that build within the system. (Clark, 1967)

\section{Norms and Values}

There is no social action (power relationships included) that is not to some degree regulated by norms and values. (Even moral and social integration from a Durkheimism perspective boils down to a normative basis.) For this writing, norms and values will be distinguished as follows. Norms are considered to be required or acceptable behavior for a specific interactional situation. Norms accomplished the task of providing an actor with standards for behaving, as well as providing standards for judging behavior. (Betrand, 1972) Finally, norms will be considered to be the smallest element of a social structure. Most social action takes place within a structure of norms and values without changing them at all, and if they are changed, the change is minimal. Two basic distinctions between norms and values will be made: (Bertrand, 1972)

1. Values derive from culture, and thus are considered matters of collective welfare.

2. Although norms also derive from culture, they are specific in nature, and apply and find their expression as rules for concrete behavior.

Furthermore, values can be distinguished from norms by making the following qualities explicit in what is meant by the concept 'values': (Bertrand, 1972)

1. Values have a conceptual element which is more profound than mere sensations, emotions, or needs.

2. Values are affectively charged, or involve some understanding which has an emotional aspect.

3. Values are not concrete goals of action, but they do relate to goals in that they serve as criteria for their selection.

4. Values are important matters and not the least trivial to the individual.

The distinction between norms and values becomes conceptually clear under the assumption that norms represent behavior which is required and fixed.

Summarily, power refers to an institutionalized set of arrangements among actors; hence, power refers to a system of norms and values. Furthermore, norms and values are specific to a particular culture. The process by which norms and values become institutionalized in the social system are quite similar to the way that a single actor gains control over another actor $(s)$. It is through the same general process of increasing the social system's members indebtedness to a skill ful leader that a system of norms and values are institutionalized that legitimate the dependency relationship. A skill- 
ful leader often allows the number of debts owed to him by other actors to increase beyond the number of demands that he makes upon the other actors in the social system. By doing this a leader increases the other actor( $\dot{s})$ indebtedness to him and insures their support. As the relationship continues, the other actors interact with one another, and with the leader. From the interaction emerges a set of norms which institutionalize and legitimate the dependency relationship. Once the norms have been established, they operate as an independent mechanism of social control. This comes about because each actor in the system is constrained in his interaction with other members of the system to conform with the generally accepted norms (Bertrand, 1972).

\section{References}

Aiken, Michael and Paul E. Hott, eds.

1968 The Structure of Community Power. New York: Random House.

Bachrach, Peter and Morton S. Baratz

1963 "Two faces of power." American Political Science Review, 57 (September)

Banfield, E. C.

1961 Political Influence. New York: Free Press.

Bertrand, Alvin W.

1972 Social Organizations. Philadelphia: F. A. Davis Publishers.

Bierstedt, Robert

1950 "An analysis of social power." American Sociological Review 15,6 (December).

Blau, Peter M.

1964 Exchange and Power in Social Life. New York: John Wiley and Sons, Inc.

Bohlen, Joe M., et al.

1965 Community Power Actors and Civil Defense: A Delineation of Community Power Actors and an Analysis of their Civil Defense Attitudes (a manual). Ames, Iowa: Iowa State University Press.

Bonjean, Charles M. and David M. 01 son

1964 "Community leadership: Directions of research." Administrative Science Quarterly, 9 (December).

Clark, Terry N.

1967 "The concept of lower: Some overemphasized and underrecognized dimensions: An examination with special reference to the local community." Social Science Quarterly, 48 (December).

Clark, Terry N., ed.

1968 Community Structure and Decision Making: A Comparative Analysis. San Francisco: Chandler Press.

Daht, Robert A.

1957 "The concept of power." Bebavioral Science, 2 (July). 
Goldhammer, H. and E. Shils

1937 "Types of power and status." American Journal of Sociology 22 (September).

Hoult, Thomas Ford

1969 Dictionary of Modern Sociology. Totowa, New Jersey: Littlefield, Adams and Company.

Lasswell, H. D. and A. Kaplan

1950 Power and Society. New Haven: Yale University Press.

Laumann, Edward 0. and Franz Urban Pappi

1973 "New directions in the study of community elites." American Sociological Review, 38, 2 (Apri1).

Litterer, Joseph A.

1969 Organizations: Structure and Behavior. New York: John Wiley and Sons, Inc.

Michels, Robert

1949 Political Parties, translated by Eden and Cedar Paul. New York: The Free Press.

Mosca, Gaetano

1939 The Ruling Class, edited by Arthur Livingston. New York: McGraw-Hill Incorporated.

Ol sen, Marvin E.

1972 Power in Societies. New York: Macmillan Co.

Pareto, Vilfredo

1966 Sociological Writings, edited by S. E. Finer. New York: F. A. Praeger,

Parsons, Talcott

1951 The Social System. Glencoe, Illinois: Free Press.

Parsons, Talcott

1968 The Structure of Social Action. New York: The Free Press.

Parsons, Talcott, et al.

1961 Theories of Society. Glencoe, Illinits: The Free Press.

Peabody, Robert L.

1964 Organizational Authority. New York: Atherton Press.

Rossi, Peter H.

1960 "Power and community structure." Midwest Journal of Political Science, IV (November).

Schermerhorn, Richard A.

1961 Society and Power. New York: Random House. 
Smel ser, Neil J. and William T. Smelser

1963 Personality and Social Systems. New York: John Wiley and Sons, Inc.

Tocqueville, Alexis de.

1961 Democracy in America. Vol. II. New York; Schocken Books.

Tonnies, Ferdinand

1957 Community and Society, translated by Charles Loomis. New York: Harper and Row, publishers.

Weber, Max

1964 The Theory of Social and Economic Organizations. New York:

The Free Press. 